\title{
Hematopoietic Radiation Injury
}

National Cancer Institute

\section{Source}

National Cancer Institute. Hematopoietic Radiation Injury. NCI Thesaurus. Code C161512.

Radiation injury of the hematopoietic system. 